Delivering medical care for patients with serious mental illness or promoting a collaborative model

\section{of recovery?}

HELEN LESTER and LINDA GASK

\section{DECONSTRUCTING RECOVERY}

There is, however, no single agreed definition of 'recovery' and indeed the largely consumerled literature from the USA suggests that it can mean different things to different people at different points in their illness pathway. William Anthony has developed a widely used definition of 'recovery' as

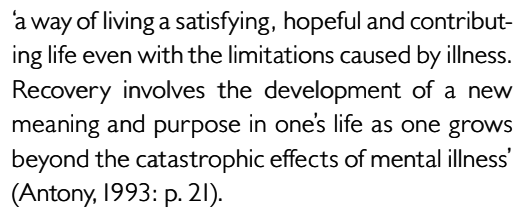

'a way of living a satisfying, hopeful and contributing life even with the limitations caused by illness. Recovery involves the development of a new meaning and purpose in one's life as one grows beyond the catastrophic effects of mental illness' (Antony, 1993: p. 21).

\section{IS SERIOUS MENTAL ILLNESS ACHRONIC CONDITION?}

A hundred years ago Emil Kraepelin suggested that once patients had been diagnosed as suffering from dementia praecox, they faced an inevitable decline towards a poor outcome (Kraepelin, 1919). In his classic 1961 text, Asylums: Essays on the Social Situation of Mental Patients and Other Inmates, Goffman described how the process of institutionalisation socialised people into the role of a good patient, someone 'dull, harmless and inconspicuous', which in turn reinforced notions of chronicity in severe mental illness (Goffman, 1968). This idea of inevitable inexorable decline has, however, become increasingly challenged by an emerging evidence base from long-term follow-up studies suggesting that approximately half the people diagnosed with a psychotic illness have a favourable outcome (Harrison et al, 2001) and that early intervention during the initial 'critical period' of a first episode of psychosis improves the chance of recovery in the short and longer term (Birchwood, 1998). There is also increasing evidence that sociocultural factors are important in the genesis of psychosis and that focusing on social recovery can improve patient outcomes (Warner, 2003).
There are also few conceptual models underpinning the notion of recovery. Strauss et al (1985) developed the theory of 'wood shedding' where, following an initial improvement, the individual's condition may 'plateau' for long periods and then suddenly improve in a discontinuous manner. More recently, Jacobson \& Greenley (2001) developed a model that encompasses both the need for internal conditions of hope, healing and empowerment experienced by the person in recovery and external conditions that facilitate recovery, such as the implementation of the principle of human rights and the development of recovery-oriented services. An overarching message from this literature is that hope and restoration of a meaningful life are possible despite a diagnosis of serious mental illness.

\section{DIFFERENT MODELS OF CARE}

With the exception of many of those working in rehabilitation services, the recovery model - despite its growing evidence base and patient support - has yet to make a significant impact on the working practices of the majority of mental health professionals in primary or secondary healthcare. Chronic care is the dominant framework.
Models of care based on 'chronic disease management', a more active approach to maximising quality of care in chronic illness, have recently found favour in policy circles (Department of Health, 2004a) and are now being widely adopted in primary and specialist care for common chronic conditions such as diabetes, depression and heart failure (more information can be obtained from the Improving Chronic Illness Care website http://www.improvingchroniccare. org). There is now evidence that models of care based on chronic disease management can improve outcomes for people with serious mental health problems (Simon et al, 2005). However, collective identification with the chronic illness 'label' fits less well with mental illness than many other chronic conditions and, in contrast to many health professionals, patients are far less likely to identify themselves as someone with a chronic illness (Lester et al, 2005). Instead, they prefer a social model of illness that emphasises recovery, at least in terms of quality of life issues such as returning to work and regaining family ties, and acknowledge the importance of patients being involved in supporting others in their recovery (Lester et al, 2005).

There are also policy tensions between frameworks such as the National Service Framework for Mental Health (Department of Health, 1999) and the more recent National Health Service Improvement Plan (Department of Health, 2004b), which emphasise chronicity, and others that highlight the importance of recovery. The Journey to Recovery (Department of Health, 2001) stated that the mental health system should support people in settings of their own choosing and enable access to community resources including housing and work or whatever they felt was critical to their own recovery. The fifth of ten essential shared capabilities for the whole mental health workforce formulated by the National Institute for Mental Health in England and the Sainsbury Centre for Mental Health in 2004 is 'promoting recovery' (Department of Health, 2004c). The National Service Framework for 'long-term conditions', although not overtly directed at mental health service users, has relevance for patients with serious mental illness and includes over 300 references to rehabilitation.

Such different policy imperatives, theoretical frameworks and aspirations for care can lead to problems in creating environments, structures and processes that encourage recovery in a way that makes sense to 
both patients and health professionals. Are we intending to deliver (mostly if not entirely) medical care for a chronic condition, or promoting collaborative models of care to improve recovery? If the latter, this raises a series of issues, including the need to develop practical methods to enable the health service and health professionals to promote recovery in practice.

\section{HOW CAN WE DEVELOP 'RECOVERY' IN PRACTICE?}

Policy contradictions are not the prerogative of mental health service planners, although they are a frequent occurrence (Glasby et al, 2003). However, there does need to be a more consistent policy direction to support and inform commissioners and providers in developing new services. At a structural level, employing people who use mental health services as a result of rather than in spite of such experience emphasises national commitment to the philosophy and practice of recovery and also contributes to social recovery at an individual level. The introduction of Support Time and Recovery workers has led to the employment of existing and former service users with a specific remit to facilitate pathways to recovery through, for example, providing companionship and friendship and helping people to live 'ordinary lives'. Within a primary care setting, the job description of graduate primary-care mental health workers now includes lived experience as a desirable quality.

The important ingredient for the individual is the underpinning philosophy of recovery that encompasses hope and therapeutic optimism within a continuing professional-patient relationship. At the level of the consultation, more attention needs to be paid to finding a shared, acceptable language that reflects new ways of framing the doctor-patient relationship. Perhaps we should actively avoid the term 'chronic disease management' and instead talk of collaborative models of care, drawing on Wagner's chronic care model (Wagner et al, 1996; Von Korff et al, 1997; also see http://www.improvingchroniccare.org). In a collaborative model, informed, activated patients, involved in their own care, are

HELEN LESTER, MB BCH, MD, FRCGP, Department of Primary Care, University of Birmingham; LINDA GASK, MB ChB, MSc, PhD, FRCPsych, Divisions of Primary Care and Psychiatry, University of Manchester, UK

Correspondence: Professor Linda Gask, University of Manchester, Division of Primary Care, Rusholme Academic Unit, Ist floor, Rusholme Health Centre, Walmer Street, Manchester MI4 5NP, UK. E-mail: Linda.Gask@manchester.ac.uk

(First received 3 August 2005, final revision 16 December 2005, accepted 2 February 2006)

the key to developing recovery-oriented services. Health professionals need to be prepared and proactive, with resources and expertise. In a collaborative doctorpatient relationship, the patient is an active participant able to make choices (for example, about medication) in partnership with a health professional. To work, this requires a professional with knowledge of the evidence base and appropriate expertise, and organisational systems and support in place to deliver care; crucially, however, the professional is able to accept that patients with serious mental illness can both reflect on their mental distress and provide a valuable understanding of their illness and treatment preferences, even if these lie outside currently recognised guidelines and protocols. Recovery-oriented services also need health professionals to believe that they can make a difference and, for some, this may mean changing the way they conceptualise the course of serious mental illness (Roberts \& Wolfson, 2004). In essence, therefore, if we want to develop recovery-oriented services for people with serious mental illness, we need to offer systematically organised and personally tailored collaborative help, treatment and care in an atmosphere of hope and optimism.

\section{REFERENCES}

Anthony, w. A. (1993) Recovery from mental illness: the guiding vision of the mental health service system in the 1990s. Psychosocial Rehabilitation Journal, 16, II-23.

Birchwood, M. (1998) Early intervention in psychosis: the critical period. In The Recognition and Management of Early Psychosis. (eds P. McGorry \& H. S. Jackson), pp. 226-264. Cambridge: Cambridge University Press.

Department of Health (1999) National Service Framework for Mental Health. London: Department of Health.
Department of Health (200I) The Journey to Recovery - The Government's Vision for Mental Health Care. London: Department of Health.

Department of Health (2004a) Improving Chronic Disease Management. London: TSO (The Stationery Office).

Department of Health (2004b) The NHS Improvement Plan. London: Department of Health.

Department of Health (2004c) The Ten Essential Shared Capabilities - A Framework for the Whole of the Mental Health Workforce. London: Department of Health.

Glasby, J., Lester, H., Clarke, M., et al (2003) Cases for Change in Mental Health Services. Colchester: National Institute for Mental Health in England.

Goffman, E. (1968) Asylums: Essays on the Social Situation of Mental Patients and Other Inmates. Harmondsworth: Penguin.

Harrison, G., Hopper, K., Craig, T., et al (200I) Recovery from psychotic illness: a 15- and 25-year international follow-up study. British Journal of Psychiatry, 178, 506-517.

Jacobson, N. \& Greenley, D. (200I) What is recovery? A conceptual model and explication. Psychiatric Services, 52, 482-485.

Kraepelin, E. (1919) Dementia Praecox and Paraphrenia. Reprinted 197I, Huntingdon, NY: Robert E. Krieger.

Lester, H. E., Tritter, J. Q. \& Sorohan, H. (2005) Providing primary care for people with serious mental illness: a focus group study. BMJ, 330, II22-1128.

Roberts, G. \& Wolfson, P. (2004) The rediscovery of recovery: open to all. Advances in Psychiatric Treatment, 10, 37-48

Simon, G. E., Ludman, E. J., Unutzer, J., et al (2005) Randomized trial of a population-based care program for people with bipolar disorder. Psychological Medicine, 35, 13-24.

Strauss, J. S., Hafez, H., Leiberman, P., et al (1985) The course of psychiatric disorder - three longitudinal principles. American Journal of Psychiatry, 142, 289-296.

Von Korff, M., Gruman, J., Schaefer, J., et al (1997) Collaborative management of chronic illness. Annals of Internal Medicine, 127, 1097-1102.

Wagner, E. H., Austin, B.T. \& Von Korff, M. (1996) Organizing care for patients with chronic illness. Milbank Quarterly, 74, 5II-544.

Warner, R. (2003) Recovery from Schizophrenia: Psychiatry and Political Economy (3rd edn). London: Brunner-Routledge. 